\title{
Getting adolescents to inform themselves about ecogenomics: a Dutch case study
}

\author{
Mark J.W. Bos, Roy R. Kloet, Cees M. Koolstra, Jaap T.J.M. Willems
}

\begin{abstract}
Public opinions toward emergent technologies may be highly dependent on the manner in which people are introduced to these technologies for the very first time. In this light, understanding how such first introductions are related to adolescents' information seeking behaviors and their developing opinions may be particularly interesting because this target public can be considered to be not only future users of the technology but also future decision makers of its development. The present paper presents a case study of the introduction of ecogenomics among 246 adolescents who were asked to inform themselves about this technology and to write two essays: one that would reflect their personal opinions, and another that would reflect their advice to the Dutch government about further funding of ecogenomics research. Results showed that the Internet was by far their preferred source of information and that most adolescents held positive attitudes toward ecogenomics as expressed in essays that reflected their personal opinions and advice to others. In their perspective, ecogenomics was a positive development in science because of expected benefits concerning medical and environmental applications, such as the potential discovery of new antibiotics and the possible use in bioremediation.
\end{abstract}

\section{Context}

The interest in science among young people in Western Europe seems to be dwindling. A drop in enrollment of students in the natural science studies has been documented in nearly all European countries. ${ }^{1,2}$ In the Netherlands this problem is especially severe: According to the Dutch government less than 20 percent of the Dutch students graduated in beta- or technical fields of study in the year $2004 .^{3}$ Despite some inclinations as to why this may occur - a lack of understanding and a lack of concern, according to Eurobarometer research ${ }^{4}$ - there has been little success in rekindling adolescents' interest in science. There is hope however. Looking at European citizens aged 15 and above, the same Eurobarometer research showed that "there is a latent interest among European citizens for science and technology, as well as an implicit demand for information." Additionally, that study found that EU citizens felt that "the relation between young people and science is essential for future prosperity of Europe." In this light, the present study aimed to investigate how young people develop opinions about an emergent technology in relation to their information seeking behaviors in an attempt to provide new insights into the interactions between science and the use of media among this particular target public.

\section{Emergent technologies, target publics, and information environments}

The past decade science and technology have developed at a rapid pace. In recent years the public was introduced to complex scientific developments such as biotechnology, nanotechnology and genomics. Sometimes the introductions of such emergent technologies raised worries or fears among the general public, but also hopes and expectations. As a result, introductions of new technologies have been an interesting research topic for science communication to better understand interactions between science and media use among the public, especially within the context of how science popularization through mass media such as television ${ }^{5}$ and newspapers affects the development of public opinions about new technologies. ${ }^{6}$ Although still dominant in science communication research, the traditional perspectives of science communication efforts (that it is aimed at conveying science information to a lay audience 
resulting in positive attitudes among this audience toward science in general or toward particular issues in science) and predominantly the concepts of scientific literacy and the deficit model have been criticized. In recent years, various authors in science communication literature have stated that it is important to realize that there are various modes of science communication - such as product-based one-way linear process (the traditional mass mediated popularization of science) and process-based two-way multidirectional processes (the more open and interactive means of science communication, generally aimed at establishing public participation in science and/or scientific research). ${ }^{7}$

One important point of criticism is that many traditional modes of science communication approach the general public as one homogeneous audience that will readily accept the presented information. While many authors will agree that there is such a thing as 'a general public' (namely all persons in society), most will also concur that in specific cases it is often necessary to distinguish between specified target publics (for example other experts or scientists, policy makers, patients). ${ }^{8}$ In this light, and from the interactive model perspective, interactions between science and society, as well as the (science) subject and (social) context, may determine how publics are formed. ${ }^{9}$ Or, as Einsiedel ${ }^{10}$ put it: "There are many and heterogeneous publics that act in social contexts and shift their attention and levels of knowledge with the rise and fall of a variety of issues." When science communication researchers and professionals are to address the problem of a dwindling interest in science among young people, they may need to increase their understanding of this particular target public.

A characteristic for science communication professionals then would be to know how this target public navigates in information environments and makes use of various media in an attempt to become informed about science. Referring to the recent developments in information technology, Miller ${ }^{11}$ stated that: "The tools for communication and learning are unparalleled in both quality and access and will undoubtedly have a substantial impact on adult information seeking and acquisition, but the nature and direction of its impact are not clear." Of course, this also holds true for adolescents. Furthermore, previous research has shown that adolescents' use of information sources differs from that among adults; as Shah and colleagues stated: "For older generations, traditional print and broadcast news sources are dominant and the Internet is supplementary. The reverse pattern holds for the young: The Internet is dominant and traditional sources supplement their needs." ${ }^{12}$ Indeed, the Internet may be of particular interest for communicating with adolescents about emergent technologies because this medium allows for "(1) frequent information updates [...], (2) multimedia formats that aid comprehension of complex concepts, and (3) access to other web sites providing more detailed information or offering differing perspectives on the technology and its applications."13

\section{Objective}

A central objective in studying how a particular target public makes use of media, is to be able to better practice science communication and to be better able to estimate potential effects of science communication efforts. Albeit somewhat strongly, Macoubrie ${ }^{14}$ for example indicated that: "Public perceptions of emergent technologies have become increasingly important to understand, in part due to the worldwide backlash against genetically modified foods, which effectively stalled a new industry."

Important lessons learned from the case of biotechnology - such as how public responses may affect policy, legislation and regulatory oversight ${ }^{15}$ - may be useful for future public introductions of emergent technologies. A confirmation of the idea that a relation between public knowledge and opinions of science may be somewhat more complex than, for example, linking public hostility toward biotechnology to a lack of understanding and inadequate media coverage, was provided by Bucchi and Neresini. ${ }^{16}$ They found that media exposure alone does not account for different attitudes toward biotechnologies. The authors indicated that these attitudes may be expected to be rooted at a deeper cultural level and that the level of education is an important factor in explaining the developing attitudes in this area. This inclination is shared by other authors, such as Brandi and colleagues, ${ }^{17}$ who found that formal education may indeed be a main catalyst that determines younger generations' views on science and technology. Unfortunately, it often seems difficult to include information about emergent technologies in formal teaching materials. In this light, schools might be a rich environment, not only for science education, but also for and as yet understudied in science communication: adolescents are still developing their information seeking behaviors, they are continuously introduced to new information, and their knowledge base as formalized in educational programs may be used by science communication 
professionals as a context within which the new emergent technology may be introduced. An additional benefit of this cross-pollination may be that adolescents become increasingly aware of the interrelatedness of the 'fixed facts of science' they learn in school and the 'dynamics and inherent uncertainties of science' that is typical for science in general and emergent technologies particularly.

As was commented by Castelfranchi and translated by Couthier, ${ }^{18}$ there is as yet little understanding of how people go about building their scientific knowledge base and imagery of science and scientists because most earlier studies were preoccupied with investigations of what people know (or do not know) about science while the process of building a knowledge base may be of key importance on how opinions are formed, stabilized, and become resistant to later external influences. Precisely because public opinions may be based on small quantities of information ${ }^{19,20}$ and because these opinions take shape within a publics' broader perspective on relations between science, technology and society ${ }^{21,22,23}$ and may be stable and resistant to later external influences - regardless of the (amount of) information retrieved or of an (admitted) lack of information - more insight into how these early opinions come about is necessary.

In this light, the present study investigated (1) how adolescents go about informing themselves about a new emergent technology. Additionally, it was studied (2) how the introduction of this technology would influence their opinions about the new technology. To this aim, adolescents were requested to write two essays: one that would explicitly reflect their opinions, and another that would reflect their advice to the Dutch government about future funding of ecogenomics research. One objective was to bring about an increased awareness among partaking adolescents of a particular emergent technology. A second objective was to gain insight into the extent to which schools might be a rich environment for science communication professionals to introduce emergent technologies among young people. The study hoped to add insight into the seeming contradiction noted by others ${ }^{24}$ that young people do seem attracted to science - especially to information about recent developments - but at the same time they seem disinclined to elaborate their information seeking behaviors in an attempt to inform themselves about scientific issues. Similar to the study of Brandi and colleagues, this study should be seen as a case study aimed at providing insight in the relevance of awareness of science as a basis for the formation of public opinion that might be interpreted in the context of identifying crucial relations between science and society, the promotion of science culture, and the implementation of science communication strategies to enhance enrollment of adolescents in the faculties of science.

The new technology considered in the present study was ecogenomics. Ecogenomics was regarded an interesting subject because, at the time of the study, it was still in a very early stage of its development cycle and our target public was unfamiliar with this new technology. ${ }^{25}$ Similar to other emergent technologies it can be expected that people will find it difficult to understand, especially when they are unfamiliar with its adjacent fields of research (here ecology, genetics and molecular biology). Furthermore, ecogenomics encompasses molecular technology and agriculture and this may lead people to perceive it as risky or undesirable because of its links to biotechnology and bio-industries - on the other hand, its relation with ecology and environmental sciences may lead people to perceive it as a beneficial technology that might be used to solve environmental problems. (According to Eurobarometer research, Europeans are most interested in news themes on environmental pollution. ${ }^{26}$ ) The Dutch Ecogenomics Consortium described ecogenomics as a technology-oriented field of research that studies ecosystems at their genetic level making use of genomics-like techniques, particularly aimed at unlocking the (genetic) potential for sustainable use of ecosystems for agricultural purposes. ${ }^{27}$ As most emergent technologies, ecogenomics may be expected to have both positive and negative societal effects and, as Roelofsen and colleagues ${ }^{28}$ put forward, the challenge for ecogenomics is to address these effects at an early stage in the development cycle - preferably by including societal actors in reflections on possible or likely opportunities and threats so as to identify desirable directions the technology may develop.

\section{Methods}

Twelve secondary schools, eighteen (biology) teachers and 246 students took part in our case study. Partaking students were aged between 15 and $19(M=17.0)$ and were all enrolled in their pre-final year at a pre-university educational level. Two ecogenomics experts collaborated in the design of the materials to warrant factual correctness of the information. 
The materials were designed using WebQuest design guidelines. WebQuests are learner-centered tasks, focused on open-ended learning goals, and encourage users to use various information resources (see http://webquest.org). ${ }^{29,30}$ The format is interesting for science communication professionals because it is considered to be inquiry-oriented and it requires people to interact with new information they themselves need to retrieve from various sources for the purpose of knowledge acquisition, integration and extension - adhering to aims of public understanding and awareness of science, as well as possibilities for public engagement in science. In accordance with the WebQuests-design guidelines, the materials provided a process description, suggestion for task evaluation (for teachers), a conclusion, and some summary information, but our focus was on its introductory text and task description. Each partaking school received one of two versions of the WebQuest. One version provided minimal (contextual) information and was labeled EcoQuest. The other version provided contextual information and was labeled BioQuest. The BioQuest version provided eleven Web site addresses that participants were suggested to access in their search for information about ecogenomics. The content of two of the eleven Web sites in BioQuest was constructed by the researchers in collaboration with two (non-partaking) biology teachers. The information on these two sites was based on existing teaching materials derived from three biology schoolbooks that are frequently used in the Netherlands and provided background knowledge about ecology and genetics. Ecology and genetics were chosen as subjects because, of all curriculum-based biology-subjects, biology teachers considered these two subjects most closely related to ecogenomics. The content of two of the eleven Web sites (two different sites than previously described) was in the English language, the information on all other Web sites was in Dutch.

To ensure the materials would be perceived as actual homework assignments, and to warrant they could be used for educational purposes as well as communication purposes, all materials were checked by ecogenomics experts, researchers at the Educational Center of VU University Amsterdam, as well as by two (non-partaking) biology teachers. The two versions were randomly distributed across the partaking schools; 118 students completed EcoQuest and 128 students completed BioQuest. Both WebQuests were introduced to participants by their regular biology teachers, who had all received written and face-to-face instructions. The teachers handed the materials to the participants during a biology class. All participants were allowed to work on the assignment for a one-week period after which they were required to hand in individual end-products. (End-products consisted of participants' answers to several questions, among which those about their information seeking behaviors, and two essays they had written about ecogenomics.) Participants were expressly instructed that they could work on the assignment at home or in school, but not during biology classes, and were free to use any and all possible information sources, including but not limited to the Internet. To ensure all products would be comparable, participants were handed a form (hardcopy as well as digitally) they were required to use - embedded within this form were our measurement instruments.

This paper reports solely on the results of our measurements of participants' reported information seeking behaviors - by asking them what sources they had used (books, brochures, Internet, magazines, newspapers, television, and human information sources), how much time they had spent using each of the selected sources (in minutes), whether they considered the retrieved information of that source useful (very useful, somewhat useful, not so useful, not useful at all), and whether they considered that source trustworthy (a lot, somewhat, or no trust). When participants indicated not to have used a particular information source in the closed question, an open question provided room to indicate why they had not included the source in their search for information. The data was used to derive a composite overview of possible or likely reasons for omitting an information source (e.g., because searching the source was expected to be unpractical and slow or generally unnecessary, the information presented in the source was expected to be scarce or outdated, or considered untrustworthy, because the source was inaccessible to the participant). For each participant, opinions about ecogenomics and advice to the Dutch government about future funding of ecogenomics research were determined through content analyses making a distinction between "all-out positive", "positive with some reservations", "negative with some reservations", and "all-out negative" (with inter-coder reliabilities of $96.4 \%$ and $89.3 \%$ ) of the two respective essays. 


\section{Results}

The Internet was found to be the preferred source of information used to search for information about ecogenomics (see Table 1). A closer look at the Web sites participants had visited during this search showed that they had used science-oriented Web sites (Web sites primarily designed for other scientists, for example the Web site of the Ecogenomics Consortium) as well as public-oriented Web sites (Web sites designed to popularize a particular science subject, for example a site popularizing genomics). Other examples were: Wikipedia, a Web site hosting a (Dutch) dictionary, Web sites of various universities (e.g., VU University Amsterdam and Wageningen University), the Web sites of a broadcasting agency (VPRO; where participants could download a previously broadcast radio-interview with two ecogenomics experts) and that of a science magazine (Bionieuws; where participants could read an article about ecogenomics). The most frequently mentioned EWeb site in the English language was that of NASA. The most frequently used search engine on the Internet was Google. Participants were found to consider the Internet both useful and trustworthy. Apart from the Internet, participants were found to have used human information sources (primarily referring to non-experts, such as classmates, family, teachers and friends - at least one participant was found to have tried to get into contact with ecogenomics experts through e-mail but he/she reported to have had no success), newspapers, magazines, books, television and brochures.

\begin{tabular}{|c|c|c|c|c|}
\hline $\begin{array}{l}\text { Type of information } \\
\text { source }\end{array}$ & User percentage & Time; range & Usability & Trust \\
\hline Internet & $\begin{array}{l}98.8 \\
(n=244)\end{array}$ & $\begin{array}{l}96.2 ; 15-270 \\
(n=219)\end{array}$ & $\begin{array}{l}3.3 \\
(n=222)\end{array}$ & $\begin{array}{l}2.8 \\
(n=232)\end{array}$ \\
\hline Human sources & $\begin{array}{l}24.4 \\
(n=242)\end{array}$ & $\begin{array}{l}20.5 ; 2-90 \\
(n=51)\end{array}$ & $\begin{array}{l}2.8 \\
(n=57)\end{array}$ & $\begin{array}{l}2.6 \\
(n=202)\end{array}$ \\
\hline Newspapers & $\begin{array}{l}6.6 \\
(n=244)\end{array}$ & $\begin{array}{l}19.6 ; 5-60 \\
(n=16)\end{array}$ & $\begin{array}{l}2.1 \\
(n=20)\end{array}$ & $\begin{array}{l}2.5 \\
(n=235)\end{array}$ \\
\hline Magazines & $\begin{array}{l}2.9 \\
(n=243)\end{array}$ & $\begin{array}{l}26.7 ; 10-60 \\
(n=6)\end{array}$ & $\begin{array}{l}2.7 \\
(n=13)\end{array}$ & $\begin{array}{l}2.3 \\
(n=221)\end{array}$ \\
\hline Books & $\begin{array}{l}1.6 \\
(n=244)\end{array}$ & $\begin{array}{l}25 ; 5-60 \\
(n=3)\end{array}$ & $\begin{array}{l}3.3 \\
(n=15)\end{array}$ & $\begin{array}{l}2.3 \\
(n=237)\end{array}$ \\
\hline Television & $\begin{array}{l}1.3 \\
(n=3)\end{array}$ & $\begin{array}{l}16.7 ; 15-20 \\
(n=3)\end{array}$ & $\begin{array}{l}1.0 \\
(n=8)\end{array}$ & $\begin{array}{l}2.3 \\
(n=230)\end{array}$ \\
\hline Brochures & $\begin{array}{l}0.8 \\
(n=244)\end{array}$ & $\begin{array}{l}33.5 ; 17-50 \\
(n=2)\end{array}$ & $\begin{array}{l}2.5 \\
(n=7)\end{array}$ & $\begin{array}{l}3.0 \\
(n=237)\end{array}$ \\
\hline
\end{tabular}

Note. Time is in minutes; usability scaled 1 to 4 ; trust scaled 1 to3. The $n$ in each cell represents the total number of participants who answered that question, these are variable because participants were only required to answer questions about how long they had used an information source and whether they thought that information source had provided useful information if they had in fact used that particular source. However, all participants were asked to indicate whether they thought science information in the listed sources was trustworthy regardless of whether or not they had used it.

Table 1. User percentage, time spent with, and perception of usability and trust for each of the seven types of information sources.

In addition to the closed questions about what information sources they had used, how much time they had spent using that source, whether they considered the retrieved information useful or not, and whether they considered it trustworthy or not, participants were free to add some information about why they had (or had not) used a particular information source. Box 1 provides some examples of the responses to this open question as an illustration of some of the participants' arguments to use a particular information source in their search for information about ecogenomics or not. 


\begin{tabular}{|ll}
\hline Books: & I did not use books because ecogenomics is so new that there probably are no books available. \\
& Besides, the internet provides all the information I need and does so in less time [information was \\
Human: & expected to be outdated and using the source as unnecessary] \\
& There are no people I know that know anything about ecogenomics, so I did not use people as \\
& information sources \\
& I asked my teacher and fellow students, but they did not know anything about ecogenomics either- \\
& they did give me some advice on where to lookfor information though [human sources were considered \\
& inaccessible or found to have no useful information] \\
Magazines: & Magazines?! I would not know where to begin: How do you search for information in \\
& magazines? What magazines would provide information about ecogenomics? [searching the \\
Internet: & source was expected to be unpractical and slow] \\
& Various websites provided enough information to complete the assignment - I did not use chat or \\
& forums because I think this would have taken too long and would not have resulted in a lot of new \\
& information and The internet is quicker and easier to use than any of the other sources - besides, \\
& it is more up-to-date as well. \\
[other sources were considered generally unnecessary or/and unpractical and slow]
\end{tabular}

Box 1. Examples of participants' reasons for using (or not using) particular information sources

Because of the low reported use of other sources, only the use of the Internet was further analyzed. These analyses showed a significant difference between participants' evaluation of the Internet's usability for information seeking purposes (Chi-square $=6.87 ; \mathrm{df}=2 ; \mathrm{p}=.032$ ), that was explained by the fact that 45.6 percent of the participants performing the EcoQuest had evaluated the Internet as very useful as compared to 30.6 percent of the participants performing the BioQuest version (51.8 versus 62.0 percent was found to consider the Internet somewhat useful and 2.6 versus 7.4 percent not so useful).

Derived from the content of the first personal opinion-essays, most participants were found to have developed positive opinions about ecogenomics. Essays $(n=240)$ were judged as being all-out positive (77.1 percent), positive with reservations (18.3 percent), negative with reservations ( 3.3 percent) or allout negative (1.2 percent) to indicate the extent to which participants held positive or negative opinions. A closer examination of the answers showed that the positive opinions were primarily based on the expectation that ecogenomics would be beneficial to the environment and on the belief that it would increase our understanding of nature and of natural processes. In some cases, however, positive opinions were also found to be based on participants' ideas that ecogenomics research would result in the discovery of new medicines or a possible breakthrough in medical research, which should not be considered a main objective of ecogenomics. ${ }^{31}$ Participants who expressed negative opinions primarily emphasized the uncertainties they perceived to surround this emergent technology, for example their doubts about the feasibility of experts' expectations about financial benefits of the technology and/or concerns about possible risks for society. Box 2 provides some example statements to reflect participants' generally positive or positive with reservations opinions about ecogenomics.

- $[\ldots]$ because of this new technology there are many new research possibilities in many fields of science (e.g. pharmaceutical science, astronomy, biology, and ecology) that may benefit from more insight in complex gene structures and what these mean for an organism or for an entire ecosystem.

- I'm relatively positive about ecogenomics. It enables us to answer many questions in ecology. For example, we may learn more about the involvement of different species exist within an ecosystem. Also, it allows us to develop methods to enhance specific factors within an ecosystem. An example is the inhibition of the spread of diseases through our soils.

- I'm relatively positive about ecogenomics. I think good research is being performed and nothing is damaged by it

- I think [ecogenomics] has many benefits when you look at the diversity of the research. When, for example, this leads to a cure for Alzheimer disease it would provide a solution for society

- I haven't found any negative things, but as yet I don't yet know everything there is to know. I'm still in doubt

Box 2. Example statements reflecting participants' personal opinions 
Most participants were also found to give a positive advice about future funding of ecogenomics research to the Dutch government. Similar to the essays that reflected their personal opinions, these essays $(n=234)$ were assessed and 58.1 percent was found to be all-out positive, 38.4 percent positive with reservations, 3.1 percent negative with reservations and 0.4 percent (one participant) all-out negative. Comparing the two essays, participants were found to use (and refer to) factual information more frequently in their adviceessays than in their personal opinion-essays. This difference was found to be significant (Chi-square = 187.63; $d f=9 ; p=.000)$. Box 3 provides a composition of some example statements to reflect participants' generally positive or positive with reservations advice about ecogenomics.

- We should not only continue finding, but extend it [...] The link with agriculture should be emphasized and possibilities for medical uses should be investigated

- It seems ecogenomics is beneficial for our economy [referring to enhanced food production] so future funding is justified [...] also, this [enhanced food production] may be beneficial for developing countries

- Ecogenomics has a lot of potential, so we should definitely fund it. However, we should also think about future legislation for these new techniques, because current laws are lacking

- During my search for information I did not find any ethical objections to ecogenomics, but there probably are some. We should find out more about it [ecogenomics] [...] However, if these [ethical objections] are few, I guess ecogenomics is acceptable

- Future funding should be balanced. Ecogenomics should not receive too much, because there are too many uncertainties. It should receive sufficient funding because we should not miss this opportunity

Box 3. Example statements reflecting participants' advice

In general, participants were found to give positive advice primarily based on hopes and expectations about future applications of ecogenomics, for example the expectation that it would solve environmental problems (e.g., "If ecogenomics can solve our environmental problems and help clean up pollution than we should invest in it, even if this means that we also need to continue research on cloning and genetic manipulation") or that it would result in medical breakthroughs (e.g., "Ecogenomics is good because it will allow us to create new medicines and cures, or prevent hereditary diseases"). Participants' positive approach was not always based on expectations about possible (or likely) output of ecogenomics research shared by experts: While ecogenomics in the Netherlands is primarily concerned with soil pollution and agriculture, some participants thought it would result in human health related benefits, such as cures for Alzheimer disease and diabetes.

Box 4 provides examples of the reservations participants had expressed in their personal opinions and advice-essays. Most reservations were found to be concerned with uncertainties about the feasibility of expected applications of ecogenomics research. In some cases, participants were found to have (ethical) objections because they thought ecogenomics was similar to, or involved with, genetic modifications of organisms. Finally, participants' reservations were also found to be based on a general objection toward human interference in nature and/or in natural processes.

- We should fund future research into the possibilities of ecogenomics before we fund further development or applications thereof; at this time it does not seem to have much added value to what we already do

- Money should be spent on projects that have a direct influence on the environment, for example protection programs, rather than on research with so many uncertainties

- [...] if things are thought-up that clean up bad stuff, or which enables us to use less dung, then it's ok - but as soon as it [ecogenomics] aims to modify animals or perform transplants between animals and humans than I disagree

- [...] still, this new science poses many threats. They [ecogenomics researchers] are messing with genes and many things can go wrong; these mistakes you cannot undo. These mistakes may start with plants, but people eat those plants and so it may also be harmful for humans

- Of course it is nice that ecogenomics helps restore ecosystems, but humans should not always want to influence everything; nature should be allowed to run its own course

- $[\ldots]$ next [soon] none of nature will be 'really' natural

Box 4. Examples of participants' reservations concerning ecogenomics 
No significant differences were found between personal opinion and advice-essays as between participants who had performed EcoQuest and BioQuest. Also, no significant differences were found between male and female participants' personal opinions, but male participants were found to advocate future funding of ecogenomics more readily than female participants (Chi-square $=8.39 ; d f=3 ; p=$ .039). A closer examination showed that 68.8 percent of the male participants had given an all-out positive advice versus 51.1 percent of the female participants (30.1 versus 44.0 percent for positive with reservations, 1.1 versus 4.3 for negative with reservations, and 0.0 versus 0.7 for all-out negative).

\section{Conclusions and discussion}

Most adolescents were found to develop positive opinions about ecogenomics and to give positive advice to the Dutch government about future funding of ecogenomics research. One reason for adolescents' general positive opinions, although one that cannot be directly derived from our research results, may be that biotechnology is a much more established and much less controversial technology to adolescents than to adults, especially because the controversy surrounding biotechnology had its peak in the 80 s and $90 \mathrm{~s}$ but is discussed in a less polarized manner in public media today. In this light, to adolescents ecogenomics may come as less of a surprise - and less of a controversial issue - than biotechnology was to their parents, although additional research is necessary to investigate this hypothesis. Regardless of the relation between ecogenomics and biotechnology, however, it may also be that people's overall attitudes toward science in general (as indicated by recent Eurobarometer studies) may determine to a large extent the initial attitudes toward emergent technologies as a reflection of people's overall trust in and approval of science. Second, this overall optimism may also be related to the developmental stage of the technology: at this time most publicly available information still originates from scientists and experts who generally emphasize possible (or expected) benefits of the technology for science and society rather than possible threats. This notion is supported be previous research, as proposed by Scheufele and Lewenstein $^{32}$ in relation to the emergence of nanotechnology: In science communication research there seems to be a premise that publics generally support development of science and technology but know little of the details of science in general ${ }^{33}$ and, in this light, it is important to realize that both positive opinions among publics and an emphasis on possible benefits of technologies for society in public media may change over time as the issue is picked up by mainstream media because in these stories there is generally a focus on controversy and fewer details (than in the texts that are currently provided by scientists and experts). Future research may focus on how the issue of ecogenomics becomes framed in the media (e.g., with a focus on environmental or biotechnological aspects) and whether or not these frames influence adolescents' opinions, and, if they do, to what extent?

The Internet was found to be the most preferred information source used for information seeking purposes by far. This overall preference was found to be based on adolescents' beliefs that this medium is easy to use and that it contains vast amounts of up-to-date and trustworthy information. It is important to note, however, that the Internet was also found to be frequently used to access information previously communicated through other media, such as radio broadcasts and articles in science magazines. So, rather than suggesting that science communication professionals should focus their efforts on popularization of science through the Internet, it might be useful to further investigate this media-interrelatedness. Somewhat surprisingly, presenting ecogenomics in the context of ecology and genetics and supplying participants with some suggestions on where to look on the Internet for information was found to result in a less positive evaluation of Internet's usability for information seeking purposes. Although there is no data within this study to support a firm conclusion, this finding may have been the result of high expectations about the usability of information that could be derived from the supplied Web sites. Various participants had expressed their surprise at the lack of information about ecogenomics that was available to them (across all media), and perhaps those who performed the BioQuest and received the Web site addresses had expected to find more readily accessible information directly related to ecogenomics. It is important to note that, by using a WebQuest format in designing our materials and by providing them with suggested Web site addresses, there may have been a bias among partaking adolescents' preference for the Internet as a source for information. However, it must be noted that during the instructions it was emphasized that partaking adolescents could use all media, the tasks were handed to them in hardcopy rather than digitally, and because no significant differences were found between 
participants' use of the Internet across the two versions of the assignment the authors feel confident that this bias was minimal.

As previously suggested by Slovic and colleagues, ${ }^{34}$ adolescents' information seeking behaviors seem to be rather intuitively and fast rather than extensively and analytically. Nonetheless, most adolescents were found to be well able to find information that they could use to write an argument-based rationale, especially in their advice-essays. However, this should not be interpreted as an indication that their information seeking behaviors had led to elaborate understanding of ecogenomics. Many adolescents were found to use copy-paste-like methods that provided relatively little insight for the researchers into how they themselves thought about the arguments and examples they provided in their essays and had retrieved from various information sources. In this light, the fact that computers enable adolescents to directly copy information from digital sources may inhibit their "deeper" information processing behaviors. It might be interesting to study this phenomenon more closely in future research.

Adolescents' unfamiliarity with the subject may also have influenced their information seeking behaviors: If partaking adolescents considered ecogenomics to have little or no personal relevance they may have been less willing to exert themselves in their search for information. And even if they did, at the time of research there was little information about ecogenomics available. Adolescents may have become frustrated about this lack of readily available information and quit their search prematurely. In this light, while the early stage of development of the technology and the lack of attention for the subject in public media was considered an important benefit at the start of this study - because this enabled us to research a target public that was exposed to minimal external influences on their developing opinions, such as framing effects - it may also be considered a limitation. Also, because the study was performed in schools and the materials were required to serve as both teaching materials and research instruments, there were limitations to the design. Future research may opt to perform a more solidly framed experiment, using a $2 \times 2$ framework to differentiate between no contextual information, providing the hyperlinks to aid information seeking behaviors, providing the constructed contextual information, and providing both the hyperlinks and the contextual information. However, in this setting, researchers may also wish to focus on learning effects rather than on participants' developing opinions and information seeking behaviors. Because this study was performed in a school-setting, all findings should be interpreted within that context and should not be directly extrapolated to out-of-school settings: It may be that adolescents' information seeking behaviors are even less extensive in out-of-school settings, especially in relation to science subjects with which they have had no direct experience or which they perceive to have little personal relevance. However, adolescents' (possible) lack of interest in science should not deter science communication professionals from making the information publicly accessible precisely because adolescents' information seeking behaviors may be expected to be less extensive in out-of-school settings. Rather, in this light the necessity of readily available and easily accessible information that is tailored to suffice in adolescents' interest in science in out-of-school settings (e.g., entertaining news about science) and possible future needs for science information in both out-of-school and in-school settings (e.g., personal interest as a result of exposure to the issue in school) seems especially important.

Further investigations of target publics' use of information sources are necessary. Our results contrast earlier findings on media use and trust in information sources ${ }^{35,36,37}$ that found that only 7 percent of participants chose the Internet as the most preferred source of information and that television, science magazines, and newspapers were the most prominently used information sources among young people. ${ }^{38}$ Especially because these earlier findings were found in the context of a public that performed information seeking behaviors in an attempt to "keeping oneself abreast and of obtaining information on topics of interest" - behaviors originating from personal interest and motivation - whereas our results were found in the context of goal-oriented and subject-specific information seeking behaviors. Apparently, science communication professionals need to be aware that medium usage, and trust in information provided by media, is highly dependent on the purpose or reason of members of a target public for accessing that medium. In general, it seems that various target publics can be expected to have very different reasons to become informed about scientific developments and initiate information seeking behaviors. In the case of this particular target public of adolescents, the Internet may be considered the preferred source of information, especially because adolescents consider this medium to provide them with readily accessible, easily searchable, fast amounts of up-to-date science information. However, more insight into the motivations to become informed (or not) and the extent to which factual information in considered 
relevant by adolescents is necessary to shed more light on this complex process in which new media formats may be expected to play an increasingly important role.

Also, precisely because of this vast amount of information, science communication professionals should be aware that simply adding information about emergent technologies may not be enough to make adolescents aware of, or interested in, the subject at hand, let alone to get adolescents to attain elaborate understanding about it. Schools may be a rich environment in which science communication professionals may interact with teachers and adolescents alike in an attempt to introduce emergent technologies within the context of a readily accessible knowledge base among their audience. Finally, and in line with findings of other studies, ${ }^{39,40}$ this study found that, regardless of the information searched and processed and the actual focus of ecogenomics research, most adolescents found health issues and solutions to environmental problems most appealing (see personal opinions-essays) and important (see advice-essays); science communication professionals may use that knowledge to attract attention for the subject of ecogenomics by emphasizing the possibilities for discovery of new antibiotics and by highlighting the aspects of bioremediation and its aims of enhancing environmental and soil quality in agricultural production.

\section{Notes and references}

1 M.C. Brandi, L. Cerbara, M. Misiti and A. Valente (2005), Youth and science in Italy: between enthusiasm and indifference, JCOM 4(2). Retrieved at March 20; available at <http://jcom.sissa.it/archive/04/02/A040201/jcom0402\%282005\%29A01.pdf>

2 K.H. Nielsen (2005), Between understanding and appreciation: current science communication in Denmark, JCOM 4(4). Retrieved March 20; available at <http://jcom.sissa.it/archive/04/04/A040402/jcom0404\%282005\%29A02.pdf>

3 The Dutch Ministry of Education, Culture and Science (2009); Retrieved March 20; available at $<$ http://www.minocw.nl/documenten/19364a.pdf>

4 European Commission, Eurobarometer Unit (2007), Europeans, Science and Technology, Special Eurobarometer 224,. Rerieved March 20; available at <http://ec.europa.eu/public_opinion/archives/ebs/ebs_224_report_en.pdf $>$

5 M.L. Nucci and R. Kubey (2007), 'We begin tonight with fruits and vegetables,' genetically modified food on the evening news 1980-2003, Science Communication, 29(2): 147-176.

6 R. Shineha, A. Hibino and K. Kato (2008), Analysis of Japanese newspaper articles on genetic modification, JCOM 7(2). Retrieved March 23; available at <http://jcom.sissa.it/archive/07/02/Jcom0702\%282008\%29A02/Jcom0702\%282008\%29A02.pdf>.

A. van der Auweraert, Dimensions of science communication, PCST-8 Conference, Barcelona, 3-6 June, 2004. Retrieved March 28; available at $<$ http://www.pcst2004.org/ing/pdf/Parallel_Session_9.pdf $>$ pp. 7-10.

8 T.W. Burns, D.J. O'Connor and S.M. Stocklmayer (2003), Science communication: a contemporary definition, Public Understanding of Science, 12(2): 183-202.

9 J. Willems and B. Regeer (2007), Publieken voor wtc: het grote publiek, deelpublieken en het publiek als expert [publics for science and technique communication: the general public, target audiences, and the public as expert], in J. Willems (red.), Basisboek wetenschapscommunicatie [Handbook science communication] pp. 209-221, The Hague: Boom Onderwijs.

${ }^{10}$ E. Einsiedel (2000), Understanding 'publics' in the public understanding of science, in: M. Dierkes \& C. von Grote (red.), Between understanding and trust: the public, science and technology, pp. 205-216, Amsterdam: Hardwood Academic Publishers.

11 J.D. Miller (2004), Public understanding of, and attitudes toward, scientific research: what we know and what we need to know, Public Understanding of Science 13(3): 273-294.

12 D.V. Shah, J.M. McLeod and S.-H. Yoon (2001), Communication, context, and community: an exploration of print, broadcast and Internet influences, Communication Research, 28(4): 464-506.

13 P.F. Byrne, D.M. Namuth, J. Harrington, S.M. Ward, D.J. Lee, and P. Hain (2002), Increasing public understanding of transgenic crops through the World Wide Web, Public Understanding of Science, 11(3): 293-304.

14 J. Macoubrie (2006), Nanotechnology: public concerns, reasoning and trust in government, Public Understanding of Science 15(2): 221-241.

15 J. Matsuura (2004), Expecting the public backlash: public relations lessons for nanotechnology from the biotechnology experience, in: Technical proceedings of the 2004 NSTI nanotechnology conference and trade show, 3. Retrieved March 28, 2009; available at <http://www.nsti.org/publications/Nanotech/2004/pdf/B3-129.pdf>

$16 \mathrm{M}$. Bucchi and F. Neresini (2006), Biotech remains unloved by the more informed: the media may be providing the message-but is anyone heeding the call?, Nature 416: 261, Retrieved March 20; available at $<$ http://www.nature.com/nature/journal/v416/n6878/pdf/416261a.pdf $>$ ${ }^{17}$ Brandi et al. 2005; see 1.

18 Y. Castelfranchi (2003), For a paleontology of the scientific imagery, JCOM 2(3). As referred to by: D. Gouthier (2007), Teachers' perception of the European scientis, JCOM 6(3). Retrieved March 20, 2009; available at $<\mathrm{http}: / /$ jcom.sissa.it/archive/06/03/Jcom0603\%282007\%29C01/Jcom0603\%282007\%29C06/Jcom0603\%282007\%29C06.pdf>

19 C.-J. Lee, D.A. Scheufele, and B.V. Lewenstein (2005), Public attitudes toward emerging technologies: examining the interactive effects of cognitions and affect on public attitudes toward nanotechnology, Science Communication, 27(2): 240-267.

20 D.A. Scheufele and B.V. Lewenstein (2005), The public and nanotechnology: how citizens make sense of emerging technologies, Journal of Nanoparticle Research 7(6): 659-667. 
${ }^{21}$ S. Murreillo, D. Contier and M. Knobel (2006), Challenges of an exhibit on nanoscience and nanotechnology, JCOM 5(4). Retrieved March 20; available at <http://jcom.sissa.it/archive/05/04/Jcom0504\%282006\%29A01/Jcom0504\%282006\%29A01.pdf>

${ }^{22}$ Lee et al. 2005; see 19

${ }_{23}$ M.D. Cobb (2005), Framing effects on public opinion about nanotechnology, Science Communication 27(2): p. $221-239$.

24 M.C.Brandi et al. 2005; see 1.

25 M.J.W Bos, C.M. Koolstra and J.T.J.M Willems (2009), Adolescents' responses toward a new technology: first associations, information seeking and affective responses to ecogenomics, Public Understanding of Science, 18(2).

26 European Commission, 2007; see 4.

27 Ecogenomics Consortium, Assessing the living soil: an ecogenomics approach to explore and unlock sustainable life-support functions of soils, Retrieved March 20, 2009; available at $<$ http://www.ecogenomics.nl $>$

${ }_{28}$ A. Roelofsen, J. E. W. Broerse, Tj. de Cock Bunning and J. F. G. Bunders (2008), Exploring the future of ecological genomics: Integrating CTA with vision assessment, Technological Forecasting and Social Change 75(3): 334-355.

${ }^{29}$ B.J. Dodge (1995), Some thoughts about WebQuests, The Distance Educator, 1(2). Retrieved March 20; available at $<$ http://webquest.sdsu.edu/about webquests.html $>$

${ }^{30}$ S.K. MacGregor and Y. Lou (2004), Web-based learning: how task scaffolding and web site design support knowledge acquisition, Journal of Research on Technology in Education 37(2): 161-175.

31 Ecogenomics Consortium; see 27.

32 D.A. Scheufele and B.V. Lewenstein (2005), The public and nanotechnology: How citizens make sense of emerging technologies, Journal of Nanoparticle Research 7(6): 659-667.

33 B.V. Lewenstein (2005), Introduction - Nanotechnology and the public, Science Communication 27(2): 169-174.

34 P. Slovic, M.L. Finucane, E. Peters and D.G. MacGregor (2004), Risk as analysis and risk as feelings: some thoughts about affect, reason, risk, and rationality, Risk Analysis 24(2): 311-322.

35 Meer vertrouwen in media dan in politiek [More trust in media than in politics], Trouw, p. 2, February 3, 2005.

${ }^{36}$ Princeton Survey Research Associates (2005), Leap of Faith: using the internet despite the dangers. Results of a national survey of internet users for Consumer Reports WebWatch. Retrieved March 20, 2009; available at

$<$ http://www.consumerwebwatch.org/pdfs/princeton.pdf $>$

${ }^{37}$ Eurobarometer (2001), Europeans, science and technology. Eurobarometer 55.2, Directorate-General for Press and communication, Public Opinion Sector.

38 Brandi et al. 2005; see 1.

39 Murriello et al. 2006; see 1.

40 European Commission, 2007; see 4.

\section{Authors}

Mark J.W. Bos is PhD student at the Department of Science Communication at the Faculty of Earth and Life Sciences, VU University Amsterdam, the Netherlands. His project deals with science communication about the emergent technology ecogenomics, focusing on adolescents' information seeking behaviors and developing opinions. E-mail: mark.bos@falw.vu.nl.

Roy R. Kloet is PhD student at the Department of Biology and Society at the Faculty of Earth and Life Sciences, VU University Amsterdam, the Netherlands. He took part in this research as part of his MSc internship. His current PhD project deals with the interactions between science, technology and society in ecogenomics. E-mail: roy.kloet@falw.vu.nl.

Cees M. Koolstra is associate professor at the Department of Communication Science at the Faculty of Social Sciences, VU University Amsterdam, the Netherlands. E-mail: cm.koolstra@fsw.vu.nl.

Jaap T.J.M. Willems is professor at the Department of Science Education \& Communication at the Faculty of Science and Technology, University of Twenty, the Netherlands.

E-mail: J.T.J.M.Willems@gw.utwente.nl.

How to cite: $\quad$ M.J.W. Bos, R.R. Kloet, C.M. Koolstra and J.T.J.M. Willems, Getting adolescents to inform themselves about ecogenomics: a Dutch case study, Jcom 08(03) (2009) A02. 